\title{
Risk Factors for Infection Following Total Joint Arthroplasty in Rheumatoid Arthritis
}

\author{
Ranjani Somayaji ${ }^{1}$, Cheryl Barnabe ${ }^{*}, 1,2$ and Liam Martin ${ }^{1}$ \\ ${ }^{1}$ Department of Medicine, ${ }^{2}$ Department of Community Health Sciences, University of Calgary, Calgary, Alberta, Canada
}

\begin{abstract}
Objective: Determine risk factors for infection following hip or knee total joint arthroplasty in patients with rheumatoid arthritis.

Methods: All rheumatoid arthritis patients with a hip or knee arthroplasty between years 2000 and 2010 were identified from population-based administrative data from the Calgary Zone of Alberta Health Services. Clinical data from patient charts during the hospital admission and during a one year follow-up period were extracted to identify incident infections.

Results: We identified 381 eligible procedures performed in 259 patients $(72.2 \%$ female, mean age 63.3 years, mean body mass index $\left.27.6 \mathrm{~kg} / \mathrm{m}^{2}\right)$. Patient comorbidities were hypertension $(43.2 \%)$, diabetes $(10.4 \%)$, coronary artery disease (13.9\%), smoking (10.8\%) and obesity (32\%). Few infectious complications occurred: surgical site infections occurred within the first year after 5 procedures ( 2 joint space infections, 3 deep incisional infections). Infections of non-surgical sites (urinary tract, skin or respiratory, $\mathrm{n}=4$ ) complicated the hospital admission. The odds ratio for any post-arthroplasty infection was increased in patients using prednisone doses exceeding $15 \mathrm{mg} /$ day (OR 21.0, 95\% $\mathrm{CI} 3.5-127.2, \mathrm{p}=<0.001$ ), underweight patients (OR 6.0, 95\% CI 1.2-30.9, $\mathrm{p}=0.033)$ and those with known coronary artery disease $(\mathrm{OR} 5.1,95 \% \mathrm{CI}$ $1.3-19.8, \mathrm{p}=0.017)$. Types of disease-modifying therapy, age, sex, and other comorbidities were not associated with an increased risk for infection.

Conclusions: Steroid doses over $15 \mathrm{mg} /$ day, being underweight and having coronary artery disease were associated with significant increases in the risk of post-arthroplasty infection in rheumatoid arthritis. Maximal tapering of prednisone and comorbidity risk reduction must be addressed in the peri-operative management strategy.
\end{abstract}

Keywords: Rheumatoid arthritis, infections, arthroplasty, administrative data.

\section{INTRODUCTION}

Despite a reduction in the need for total joint arthroplasty (TJA) in the management of end-stage damage of the hip and knee in rheumatoid arthritis (RA) [1-5], many patients still require procedures to restore function and quality of life. It has been suggested that RA patients are at increased risk for post-operative complications such as infection [6], attributed to traditional patient risk factors such as age, smoking status, and obesity, in addition to the risk of immunosuppressive therapies.

Post-operative infections cause morbidity, and in the case of prosthetic joint infections the potential need for future revision procedures. Modifiable risk factors should be identified in order to optimize surgical outcomes. A recent systematic review highlights that knowledge of TJA infection risk in RA is actually quite limited [6]. As well, the literature focuses on surgical site and prosthetic joint infections, and neglects the risk for infections of other sites which may complicate the hospital course. The purpose of our study was to determine both the patient and therapeutic risk factors for both surgical site infections in the first year

*Address correspondence to this author at the 3330 Hospital Dr. NW, Calgary, AB CANADA T2N 4N1, Canada; Tel: (403) 220-7725;

Fax: (403) 283-5666; E-mail: ccbarnab@ucalgary.ca post-procedure, and other organ infections occurring during the surgical admission in a population-based RA cohort.

\section{METHODS}

\subsection{Patients}

Subjects were identified from population-based administrative datasets from the Calgary Zone of Alberta Health Services, Canada from the fiscal years 2000/2001 to the end of fiscal year 2010/2011. These datasets reflect records generated by both trained hospital separation coders and submitted physician billing claims, yielding high accuracy in case identification. This Zone has three tertiary care hospitals where TJA is performed and serves a catchment area of 1.5 million individuals in the province of southern Alberta. We first identified subjects with procedure codes for primary and revision hip or knee TJA (VA.53.LAPN, VG.53.LAPN, VG.53.LAPP) to the end of December 2010 (which allowed for a one year follow-up period for post-operative infection). We then selected the cohort who also had a diagnostic code for RA in any of the years of the study (International Classification of Diseases, $9^{\text {th }}$ Revision, Clinical Modification (ICD-9-CM) 714.x for fiscal years 2000-2002, or 10th Revision, Canadian Adaptation (ICD-10-CA) M05.x or M06.x for fiscal years 2002-2010). All diagnoses and procedures were verified at the data extraction stage. 


\subsection{Data Extraction}

Age and sex, comorbidities as diagnosed by physicians (including diabetes, hypertension, coronary artery disease), and smoking status were recorded from the pre-operative assessment. The height and weight at the time of surgery were extracted from the chart. Medications, including nonbiologic disease-modifying anti-rheumatic drugs (DMARDs, including methotrexate, sulfasalazine, leflunomide, hydroxychloroquine), and biologic agents (infliximab, adalimumab, etanercept, golimumab, rituximab, abatacept and anakinra) as well as corticosteroid use and dose were noted. For patients receiving a biologic agent, the timing of last dose prior to surgery was recorded. Surgical procedures were recorded as primary hip or knee arthroplasty and revision arthroplasty based on procedure coding and chart review. These procedures included both elective and emergent procedures (i.e. hip arthroplasty following a hip fracture). The duration of disease, level of disease activity and functional level scores are not recorded in the hospital chart and it is not possible to include these data in our analyses.

\subsection{Outcomes}

Surgical site infections (SSI) were characterized in accordance with the Centres for Disease Control criteria [7]. This classification recognizes superficial incisional, deep incisional, and space infections of the joint. We used chart documentation of symptoms and signs of infection to determine the location and severity of infection, antibiotic treatment, or need for re-hospitalization and repeat surgery. This was supported by confirmation of diagnostic imaging results, microbiology testing and outpatient home parenteral therapy program notes. We also extracted details on infections of other sites during the index surgical admission. These data were reviewed by two internal medicine physicians (RS and $\mathrm{CB}$ ).

\subsection{Independent Variables}

These were selected based on the existing literature for patient risk factors for infections after TJA. Factors examined included patient sex, age, obesity (body mass index $>30 \mathrm{~kg} / \mathrm{m}^{2}$ ), smoking status (current, past, never), and the three most common comorbid conditions in the cohort (hypertension, diabetes, and coronary artery disease). Therapeutic classes for RA treatment were also examined, including prednisone, non-biologic DMARDs (any) and biologics (any).

\subsection{Statistical Analysis}

Univariate logistic regression models were constructed to calculate the odds ratio (OR) for any post-arthroplasty infection based on the independent variables above. Our priori research plan indicated that a multivariate model would be constructed however the small number of infectious events limited our ability to do this. All analysis was performed using STATA version 11.2 (College Station, Texas).

\subsection{Ethics}

Ethics approval was granted by the Conjoint Health Research Ethics Board of the University of Calgary.

\section{RESULTS}

\subsection{Procedures}

From the administrative data, we identified 420 hip or knee replacement surgeries in RA patients performed over 10 years. Of these, 35 were excluded from further analysis as the diagnosis of RA was not confirmed on chart review, and 4 charts could not be retrieved. The remaining 381 procedures were performed in 259 individuals. The procedures consisted of 137 total hip arthroplasties and 244 total knee arthroplasties. Of these, 345 procedures were done electively, 29 procedures were a revision surgery, and 7 arthroplasties were performed secondary to a fracture.

\subsection{Patients}

The patients' demographic data are reported in Table 1. In summary, $72.2 \%$ were female, with a mean age of 63.3 years. The mean body mass index was $27.6 \mathrm{~kg} / \mathrm{m}^{2}$, and $32.0 \%$ classified as obese. Nearly half of the patients had hypertension $(43.2 \%)$, followed in frequency by coronary artery disease $(13.9 \%)$, and diabetes $(10.4 \%)$. There were 28 $(10.8 \%)$ current smokers in the cohort. Nine patients had a history of a prior prosthetic joint infection of another joint, with 1 having 2 prior prosthetic joint infections.

Table 1. Clinical Characteristics of Study Patients

\begin{tabular}{|c|c|c|}
\hline Characteristic & & Number (\%) \\
\hline Female & & $187(72.2 \%)$ \\
\hline Age, years & & $\begin{array}{l}\text { mean } 63.3 \\
(\mathrm{SD} 14.1)\end{array}$ \\
\hline Smoking & $\begin{array}{l}\text { Current } \\
\text { Past } \\
\text { Never }\end{array}$ & $\begin{array}{l}28(10.8 \%) \\
40(15.4 \%) \\
191(73.8 \%)\end{array}$ \\
\hline Body Mass Index & $\begin{array}{l}\text { Mean } \\
\text { Obese }(>30.0)\end{array}$ & $\begin{array}{l}27.6(7.0) \\
83(32.0 \%)\end{array}$ \\
\hline Comorbidity & $\begin{array}{l}\text { Hypertension } \\
\text { Diabetes } \\
\text { Coronary artery disease } \\
\text { Chronic Obstructive Lung Disease } \\
\text { Chronic Renal Failure } \\
\text { No comorbid conditions } \\
\geq 2 \text { Comorbid conditions }\end{array}$ & $\begin{array}{l}112(43.2 \%) \\
27(10.4 \%) \\
36(13.9 \%) \\
11(4.3 \%) \\
8(3.1 \%) \\
114(44.0 \%) \\
38(14.7 \%)\end{array}$ \\
\hline
\end{tabular}

At the time of surgery, $67.5 \%$ of patients were being treated with either biologics or non-biologic DMARDs ( $\mathrm{n}=$ $257 / 381$ procedures) (Table 2). RA treatment varied over the course of the study, with biologic and non-biologic DMARD 
therapy increasing over time (Fig. 1). For 14 of the patients $(20.0 \%)$ on biologic therapy, this therapy was not held in the pre-operative period. With regards to steroid use, $27.4 \%$ of patients were taking between 1 and $15 \mathrm{mg} /$ day of prednisone at the time of surgery, and $1.9 \%$ were taking $>15 \mathrm{mg} /$ day (Table 2). Nearly all patients $(96.8 \%)$ received antimicrobial prophylaxis prior to surgery.

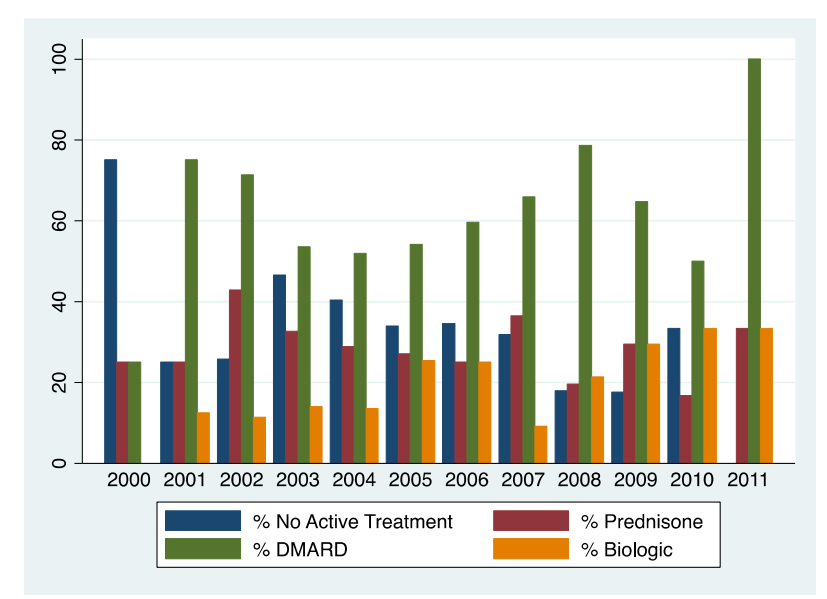

Fig. (1). Therapy Used by Arthroplasty Patients, by Year of Surgical Procedure.

Table 2. Therapy at Time of Surgery

\begin{tabular}{|c|l|l|}
\hline Therapeutic Class & & Number (\%) \\
\hline \hline Prednisone & None & $268(70.7 \%)$ \\
& $0.5-15 \mathrm{mg} / \mathrm{day}$ & $104(27.4 \%)$ \\
& $>15 \mathrm{mg} / \mathrm{day}$ & $7(1.9 \%)$ \\
\hline DMARDs, Total Exposed & & $235(61.2 \%)$ \\
& Methotrexate & $145(38.1 \%)$ \\
& Hydroxychloroquine & $117(30.7 \%)$ \\
& Sulfasalazine & $20(5.3 \%)$ \\
& Leflunomide & $34(8.9 \%)$ \\
& Combination DMARDs & $84(22.1 \%)$ \\
\hline \multirow{2}{*}{ Biologics, Total Exposed } & & $70(18.4 \%)$ \\
& Infliximab & $14(3.7 \%)$ \\
& Adalimumab & $15(3.9 \%)$ \\
& Etanercept & $36(9.5 \%)$ \\
& Golimumab & $1(0.3 \%)$ \\
& Anakinra & $2(0.5 \%)$ \\
& Abatacept & $1(0.3 \%)$ \\
& Rituximab & $1(0.3 \%)$ \\
\hline \multirow{5}{*}{} & &
\end{tabular}

\subsection{Surgical Site Infections}

Surgical site infections (SSI) were infrequent, only occurring after 5 procedures during the 1 year follow-up period. These included 2 joint space infections, and 3 deep incisional infections. Details of the surgery and infection are found in Table 3. All of these required repeated surgical intervention and prolonged antibiotic courses for resolution.

\subsection{Post-Operative Infections}

Four hospital admissions were complicated by infections of non-surgical sites (urinary tract, skin or respiratory). Specific details on the infection appear in Table $\mathbf{3}$.

\subsection{Risk Factors for Infection Following Arthroplasty}

Univariate analysis was used to explore the association between post-arthroplasty infections (pooled) and patient risk factors (Table 4).

The odds ratio of any post-arthroplasty infection was increased in patients using prednisone doses exceeding 15 $\mathrm{mg}$ /day (odds ratio $21.0,95 \%$ CI 3.5-127.2, $\mathrm{p}=<0.001$ ), but not for patients exposed to $<15 \mathrm{mg} / \mathrm{day}$. Coronary artery disease was also associated with an increased risk for infection (odds ratio 5.1, 95\%CI 1.3-19.8, $\mathrm{p}=0.017$ ). Although we were expecting an increased risk of infection in obese patients, it was actually underweight patients (BMI $<18.5 \mathrm{~kg} / \mathrm{m}^{2}$ ) who had a significant risk (odds ratio 6.0 , $95 \%$ CI 1.2-30.9, $\mathrm{p}=0.033$ ). DMARDs and biologic therapies, not being on RA treatment, and age, sex, smoking status and other comorbidities of hypertension and diabetes were not associated with an increased risk for infection.

\section{DISCUSSION}

Our retrospective population-based study of 10 years of outcomes of arthroplasty surgery in a Canadian centre shows very few surgical site infections occurring in RA patients. Infections during the hospital course were also rare. In the few cases of infection, a strong association with corticosteroid exposure was apparent, particularly with doses $>15 \mathrm{mg}$ /day being associated with a 20 -fold increased risk. Other significant risk factors for post-arthroplasty infection were being underweight and a patient history of coronary artery disease.

The risk for serious infections in RA is driven by age, disease severity, systemic inflammation and comorbid disease [8]. RA patients are known to be at heightened risk for infection following orthopedic procedures [9-15], plausibly related to the influence of disease factors on surgical healing. To our knowledge, the risk of infection associated with coronary artery disease and low body mass has not been described specifically in orthopedic procedures. Interestingly, a recent study looking at readmissions following arthroplasty found that these factors were associated with an increased risk of readmission, although not necessarily for infections [16]. We believe coronary artery disease and low body mass likely reflect high disease burden in patients with RA, and those with the most severe alterations in immunity. Thus, efforts to effectively manage RA will likely decrease both the need for TJA and surgical risk over time.

Modifying and managing RA therapy in the perioperative period is critical in reducing the risk of infection. Chronic corticosteroid exposure is again confirmed in our study to significantly increase the risk for infection, 
Table 3. Descriptions of Post-Arthroplasty Infections

\begin{tabular}{|c|c|c|c|}
\hline Surgery: Joint and Type & $\begin{array}{c}\text { Post-Operative Infection: Type } \\
\text { and Organism }\end{array}$ & Patient Risk Profile & Management \\
\hline Knee arthroplasty, primary & $\begin{array}{c}\text { Joint Space Infection, Coagulase } \\
\text { negative Staph }\end{array}$ & Chronic viral hepatitis & $\begin{array}{l}\text { Drained seroma, antibiotics; } \\
\text { eventual resection with spacer and } \\
\text { further revision required }\end{array}$ \\
\hline $\begin{array}{l}\text { Knee arthroplasty, } \\
\text { revision }\end{array}$ & $\begin{array}{l}\text { Joint Space Infection, } \\
\text { S. aureus }\end{array}$ & $\begin{array}{c}\text { Prednisone } 15 \mathrm{mg} / \mathrm{day} \text {, coronary } \\
\text { artery disease }\end{array}$ & $\begin{array}{c}\text { Surgical debridement, antibiotics, } \\
\text { revision surgery }\end{array}$ \\
\hline Knee arthroplasty, primary & $\begin{array}{l}\text { Deep incisional, } \\
\text { S. aureus and Enterococcus }\end{array}$ & $\begin{array}{c}\text { Prednisone } 10 \mathrm{mg} / \text { day, obesity, } \\
\text { diabetes, coronary artery disease, } \\
\text { hypertension }\end{array}$ & $\begin{array}{l}\text { Surgical debridement, } \\
\text { prolonged antibiotics }\end{array}$ \\
\hline Knee arthroplasty, primary & $\begin{array}{c}\text { Deep incisional, no organism } \\
\text { cultured }\end{array}$ & None & $\begin{array}{l}\text { Wound debridement, removal of } \\
\text { hematoma, antibiotics }\end{array}$ \\
\hline $\begin{array}{l}\text { Hip arthroplasty, revision for } \\
\text { fracture }\end{array}$ & $\begin{array}{c}\text { Deep incisional, Enterococcus } \\
\text { faecalis }\end{array}$ & $\begin{array}{l}\text { Prednisone } 17.5 \mathrm{mg} \text { daily, } \\
\text { hypertension, diabetes, coronary } \\
\text { artery disease, osteomyelitis foot }\end{array}$ & $\begin{array}{l}\text { Incision and drainage, prolonged } \\
\text { antibiotics }\end{array}$ \\
\hline Hip arthroplasty, primary & Urinary tract & $\begin{array}{l}\text { Leflunomide and adalimumab, } \\
\text { hypertension }\end{array}$ & Antibiotics \\
\hline Hip arthroplasty, primary & Urinary tract & Prednisone $10 \mathrm{mg} /$ day, age $>65$ & Antibiotics \\
\hline Knee arthroplasty, revision & Cellulitis of posterior shin & Age $>65$, coronary artery disease & Antibiotics \\
\hline Knee arthroplasty, primary & Pneumonia & $\begin{array}{c}\text { Prednisone } 5 \mathrm{mg} / \text { day, Leflunomide, } \\
\text { age }>65\end{array}$ & Antibiotics \\
\hline
\end{tabular}

Table 4. Univariate Analysis, Risk Factors for Post-Operative Infection

\begin{tabular}{|l|r|c|}
\hline & Odds Ratio (95\%CI) & p Value \\
\hline \hline Age $>65$ years & $2.19(0.27-17.78)$ & 0.463 \\
\hline Female & $2.06(0.54-7.83)$ & 0.288 \\
\hline Obesity $\left(\mathrm{BMI}>30 \mathrm{~kg} / \mathrm{m}^{2}\right)$ & $0.24(0.03-1.90)$ & 0.175 \\
\hline Underweight $\left(\mathrm{BMI}<18.5 \mathrm{~kg} / \mathrm{m}^{2}\right)$ & $5.97(1.15-30.9)$ & - \\
\hline Current Smoker & no events & 0.033 \\
\hline Per Comorbid Condition & $1.17(0.49-2.76)$ & 0.723 \\
\hline Hypertension & $0.71(0.18-2.89)$ & 0.293 \\
\hline Diabetes & $2.36(0.47-11.77)$ \\
\hline Coronary Artery Disease & $5.14(1.33-19.77)$ & 0.017 \\
\hline Prednisone Exposure (Any) & $3.06(0.81-11.60)$ & 0.101 \\
\hline Prednisone $>15$ mg/day & $20.97(3.46-127.16)$ & 0.001 \\
\hline DMARD therapy & $0.77(0.20-2.92)$ & 0.703 \\
\hline Biologic therapy & $0.55(0.07-4.46)$ & 0.575 \\
\hline Not on DMARD or biologic therapy & $1.68(0.44-6.37)$ \\
\hline
\end{tabular}

Legend: DMARD disease-modifying anti-rheumatic drug.

consistent with the study by Gilson et al, where joint space infections following TJA in patients on anti-TNF therapy were analyzed, with an odds ratio for infection increasing 5 fold for every $5 \mathrm{mg}$ /day increase in prednisone dose [17]. The risk for infection conferred by steroids have been further confirmed in studies by Kawakami et al. [18] and Salliot et al. [19]. Corticosteroids impair phagocyte function and suppress cell-mediated immunity [20]. Given the consistency and strength of the association between corticosteroids and infection, this should be the primary target in patient management.

In contrast, non-biologic DMARDs to not confer an increased risk of infection, either in our study or many others [17-19, 21-24]. The long half-life of these agents precludes effective discontinuation and resumption without risking flare and worsening of disease control. We do not recommend discontinuation of non-biologic DMARDs 
unless delayed wound healing or infection is experienced in the post-surgical period.

The risk of infections conferred by the use of biologic therapies in patients undergoing orthopedic surgery is as yet unresolved in the literature. It is known that tumor necrosis factor-alpha (TNF-alpha), the first widely used target of biologic therapy, plays a critical role in the regulation of inflammatory processes to mount a response to infection [25]. TNF-alpha also plays an important role in wound healing with effects on angiogenesis, fibroblast proliferation, and collagen synthesis [26]. Our study did not show an increased risk of infection post-operatively with biologic use which adds to the body of conflicting literature in this area. Two prospective cohort studies have showed increased infection risk with use of biologics in RA patients undergoing surgeries in contrast to previous case-control and retrospective studies. Giles et al. determined a serious (deep) orthopedic infection rate of $11 \%$ and a 4 -fold increased risk in patients receiving TNF-alpha inhibitors [22], and Momohara et al. reported a $6.4 \%$ superficial or deep postoperative infection rate with a 9-fold increased risk despite discontinuation of therapy pre-operatively [21]. Given the conflicting evidence, there are no standardized guidelines for the management of biologic therapies in the management of patients in the peri-operative period. The American College of Rheumatology suggests that anti-TNF be held for at least 1 week prior to and following surgery [27]. In contrast, the Canadian guidelines are more variable ranging from 1 week -2 months depending on the biologic, nature of the surgery and patient characteristics [28]. In our centre, nurse specialists work alongside physicians in the Biologics Pharmacosurveillance program, with advice on peri-operative management tailored to the patient's current therapy and comorbidities.

We acknowledge limitations of our study. We used administrative data to identify all surgical events occurring in our health Zone, with hospital chart review to confirm significant post-operative infectious events in the first year following surgery. It is likely that patients sought care for minor infectious complications outside of the hospital and this would reduce identification of superficial infection. It is expected though that all serious complications and certainly those requiring re-admission to hospital or repeat surgeries would be captured unless the patient migrated to a new health Zone or out of province.

Relatively few infection events occurred, and thus the power to detect significant risk factors is reduced. This limitation exists in the majority of the literature surrounding peri-operative infection in RA patients. Additionally, multiple surgeries in individual patients were considered as independent events although one event may affect the next regardless of timing and thus make the statistical assumptions false. However, all of the outcomes occurred in different patients and not in patients with previous prosthetic infections, and thus did not likely alter our results. Finally, disease activity level and function are not captured in the hospital chart, and therefore we cannot comment on the role that these factors played in post-operative infection risk.

In summary, we found that the use of corticosteroids increased the risk of post-operative infection in RA patients undergoing large joint arthroplasty especially at doses
$>15 \mathrm{mg} /$ day. Coronary artery disease and being underweight were also associated with post-operative and surgical site infections. DMARDs and biologic therapies did not confer an increased risk of infection in the post-operative period, and the role of comorbidities will need to be studied further to determine their influence of post-operative infection risk. The optimal management of the RA patient in the perioperative period should focus primarily on reduction in corticosteroid use and adherence to recommendations on cessation of biologic therapy.

\section{CONFLICT OF INTEREST}

The authors confirm that this article content has no conflict of interest.

\section{ACKNOWLEDGEMENTS}

Declared none.

\section{REFERENCES}

[1] Massardo L, Gabriel SE, Crowson CS, et al. A population based assessment of the use of orthopedic surgery in patients with rheumatoid arthritis. J Rheumatol 2002; 29(1): 52-6

[2] da Silva E, Doran MF, Crowson CS, et al. Declining use of orthopedic surgery in patients with rheumatoid arthritis? Results of a long-term, population-based assessment. Arthritis Rheum 2003; 49 (2): 216-20.

[3] Louie GH, Ward MM. Changes in the rates of joint surgery among patients with rheumatoid arthritis in California, 1983-2007. Ann Rheum Dis 2010; 69(5): 868-7.1

[4] Hekmat K, Jacobsson L, Nilsson JA, et al. Decrease in the incidence of total hip arthroplasties in patients with rheumatoid arthritis--results from a well defined population in south Sweden. Arthritis Res Ther 2011; 13(2): R67.

[5] Shourt CA, Crowson CS, Gabriel SE, et al. Orthopedic surgery among patients with rheumatoid arthritis 1980-2007: a populationbased study focused on surgery rates, sex, and mortality. J Rheumatol 2012; 39(3): 481-5.

[6] Ravi B, Escott B, Shah PS, et al. A systematic review and metaanalysis comparing complications following total joint arthroplasty for rheumatoid arthritis versus for osteoarthritis. Arthritis Rheum 2012; 64(12): 3839-49.

[7] Horan TC, Gaynes RP, Martone WJ, et al. CDC definitions of nosocomial surgical site infections, 1992: a modification of CDC definitions of surgical wound infections. Infect Control Hosp Epidemiol 1992; 13(10): 606-8

[8] Crowson CS, Hoganson DD, Fitz-Gibbon PD, et al. Development and validation of a risk score for serious infection in patients with rheumatoid arthritis. Arthritis Rheum 2012; 64(9): 2847-55.

[9] Bongartz T, Halligan CS, Osmon DR, et al. Incidence and risk factors of prosthetic joint infection after total hip or knee replacement in patients with rheumatoid arthritis. Arthritis Rheum 2008; 59(12): 1713-20.

[10] Bengtson S, Knutson K. The infected knee arthroplasty. A 6-year follow-up of 357 cases. Acta Orthop Scand 1991; 62(4): 301-11

[11] Robertsson O, Knutson K, Lewold S, et al. The Swedish Knee Arthroplasty Register 1975-1997: an update with special emphasis on 41,223 knees operated on in 1988-1997. Acta Orthop Scand 2001; 72(5): 503-13.

[12] Wilson MG, Kelley K, Thornhill TS. Infection as a complication of total knee-replacement arthroplasty. Risk factors and treatment in sixty-seven cases. J Bone Joint Surg Am 1990; 72(6): 878-83.

[13] Wymenga AB, van Horn JR, Theeuwes A, et al. Perioperative factors associated with septic arthritis after arthroplasty. Prospective multicenter study of 362 knee and 2,651 hip operations. Acta Orthop Scand 1992; 63(6): 665-71.

[14] Berbari EF, Hanssen AD, Duffy $\mathrm{MC}$, et al. Risk factors for prosthetic joint infection: case-control study. Clin Infect Dis 1998; 27(5): 1247-54 
[15] Jamsen E, Huhtala H, Puolakka T, et al. Risk factors for infection after knee arthroplasty. A register-based analysis of 43,149 cases. J Bone Joint Surg Am 2009; 91(1): 38-47.

[16] Saucedo JM, Marecek GS, Wanke TR, et al. Understanding Readmission After Primary Total Hip and Knee Arthroplasty: Who's at Risk? J Arthroplasty 2013 [Epub ahead of print].

[17] Gilson M, Gossec L, Mariette X, et al. Risk factors for total joint arthroplasty infection in patients receiving tumor necrosis factor alpha-blockers: a case-control study. Arthritis Res Ther 2010; 12(4): R145.

[18] Kawakami K, Ikari K, Kawamura K, et al. Complications and features after joint surgery in rheumatoid arthritis patients treated with tumour necrosis factor-alpha blockers: perioperative interruption of tumour necrosis factor-alpha blockers decreases complications? Rheumatology (Oxford) 2010; 49(2): 341-7.

[19] Salliot C, Gossec L, Ruyssen-Witrand A, et al. Infections during tumour necrosis factor-alpha blocker therapy for rheumatic diseases in daily practice: a systematic retrospective study of 709 patients. Rheumatology (Oxford) 2007; 46(2): 327-34.

[20] Cutolo M, Seriolo B, Pizzorni C, et al. Use of glucocorticoids and risk of infections. Autoimmun Rev 2008; 8(2): 153-5.

[21] Momohara S, Kawakami K, Iwamoto T, et al. Prosthetic joint infection after total hip or knee arthroplasty in rheumatoid arthritis patients treated with nonbiologic and biologic disease-modifying antirheumatic drugs. Mod Rheumatol 2011; 21(5):469-75.

[22] Giles JT, Bartlett SJ, Gelber AC, et al. Tumor necrosis factor inhibitor therapy and risk of serious postoperative orthopedic infection in rheumatoid arthritis. Arthritis Rheum 2006; 55(2): 3337.

[23] Ruyssen-Witrand A, Gossec L, Salliot C, et al. Complication rates of 127 surgical procedures performed in rheumatic patients receiving tumor necrosis factor alpha blockers. Clin Exp Rheumatol 2007; 25(3): 430-6

[24] den Broeder AA, Creemers MC, Fransen J, et al. Risk factors for surgical site infections and other complications in elective surgery in patients with rheumatoid arthritis with special attention for antitumor necrosis factor: a large retrospective study. J Rheumatol 2007; 34(4): 689-95

[25] Ellerin T, Rubin RH, Weinblatt ME. Infections and anti-tumor necrosis factor alpha therapy. Arthritis Rheum 2003; 48(11): 301322.

[26] Busti AJ, Hooper JS, Amaya CJ, et al. Effects of perioperative antiinflammatory and immunomodulating therapy on surgical wound healing. Pharmacotherapy 2005; 25(11): 1566-91.

[27] Saag KG, Teng GG, Patkar NM, et al. American College of Rheumatology 2008 recommendations for the use of nonbiologic and biologic disease-modifying antirheumatic drugs in rheumatoid arthritis. Arthritis Rheum 2008; 59(6): 762-84.

[28] Bombardier C, Hazlewood GS, Akhavan P, et al. Canadian Rheumatology Association recommendations for the pharmacological management of rheumatoid arthritis with traditional and biologic disease-modifying antirheumatic drugs: part II safety. J Rheumatol 2012; 39(8): 1583-602.

(c) Somayaji et al.; Licensee Bentham Open.

This is an open access article licensed under the terms of the Creative Commons Attribution Non-Commercial License (http://creativecommons.org/licenses/by-nc/ 3.0/) which permits unrestricted, non-commercial use, distribution and reproduction in any medium, provided the work is properly cited. 